\title{
Performance assessment of a ductless personalized ventilation system using a validated CFD model
}

\author{
Hayder Alsaad, Conrad Voelker \\ Bauhaus-University Weimar, Department of Building Physics \\ Coudraystrasse 11A, Room 110 \\ 99423 Weimar, Germany \\ Email: hayder.alsaad@uni-weimar.de,conrad.voelker@uni-weimar.de
}

(Received 19 November 2017; accepted 20 January 2018; published online 08 February 2018)

\section{Copyright Notice}

Copyright 2018 Taylor \& Francis Group and the International Building Performance Simulation Association (IBPSA). This article may be downloaded for personal use only. Any other use requires prior permission of the authors and Taylor \& Francis Group.

This is an Accepted Manuscript of an article published by Taylor \& Francis in the Journal of Building Performance Simulation 11 (6), 689-704 (2018) and may be found at https://doi.org/10.1080/19401493.2018.1431806

\footnotetext{
Abstract

The aim of this study is twofold: to validate a computational fluid dynamics (CFD) model, and then to use the validated model to evaluate the performance of a ductless personalized ventilation (DPV) system. To validate the numerical model, a series of measurements was conducted in a climate chamber equipped with a thermal manikin. Various turbulence models, settings, and options were tested; simulation results were compared to the measured data to determine the turbulence model and solver settings that achieve the best agreement between the measured and simulated values.

Subsequently, the validated CFD model was then used to evaluate the thermal environment and indoor air quality in a room equipped with a ductless personalized ventilation system combined with displacement ventilation. Results from the numerical model were then used to quantify thermal sensation and comfort using UC Berkeley thermal comfort model.
} 


\section{Introduction}

Buildings are equipped with mechanical systems to maintain a sufficient level of thermal comfort and indoor air quality. These systems control the physical environmental factors reported by Fanger (1970) that affect human comfort, such as air temperature, air velocity, and relative humidity. However, total volume ventilation systems that are commonly used in building nowadays treat the whole volume of the space which consumes a significant amount of energy (Lipczynska, Kaczmarczyk, and Melikov 2014).

Personalized ventilation (PV) is a system that provides fresh air to the occupants' breathing zone. It allows individual control over air velocity, direction, and possibly temperature too (Melikov 2004a). Thus, it treats the air around the occupants rather than the whole volume of the room, while a background total volume ventilation system treats the rest of the space as the flow rate of PV is usually not big enough to achieve the required air exchange rate and thermal comfort requirements in the whole space.

Ductless personalized ventilation (DPV) is a mean of bringing cool fresh air from the lower level of the room and delivering it directly to the occupants' face. It is used in combination with displacement ventilation (DV) due to the vertical stratification created by this ventilation system (Halvoňová and Melikov 2010). In order to avoid transporting pollutants from the floor level to the occupant's face region and to enhance the perceived air quality, it is recommended to install a filter at the intake of the system (Dalewski, Vesely, and Melikov 2012). 'Ductless' personalized ventilation is - as the name suggests - a self-standing system that is not connected to a duct that supplies fresh tempered air from the outdoor. Hence, unlike regular 'ducted' personalized ventilation systems, it does not require additional ductwork. Furthermore, DPV does not restrict the arrangement of furniture in the room, and thus, it does not affect its aesthetics (Dalewski, Melikov, and Vesely 2014). DPV is not as widely examined in literature as regular ducted personalized ventilation. Therefore, this study aims to evaluate the performance of the system using CFD simulations.

Computational fluid dynamics (CFD) is a branch of applied mathematics that solves problems of fluid flows using numerical simulations (Kuzmin 2010). CFD is a powerful research tool that has been utilized in indoor air distribution research since the 1970s (Nielsen 2015). It allows conducting 'virtual experiments' in a 'virtual laboratory' which is more convenient, faster, and cheaper than empirical studies (Kuzmin n.d.). Before conducting CFD simulations, it is necessary to validate the numerical model against measured data. ASHRAE handbook states that Validation provides 'instructions on how to demonstrate the coupled ability of a user and a CFD code to accurately conduct representative indoor environmental simulations with available experimental data against measured data' (ASHRAE 2009).

To accurately predict the behaviour of a turbulent flow, a suitable turbulence model must be chosen in the CFD solver.
Among several available models, the two-equation turbulence model $\mathrm{k}-\varepsilon$ was chosen for this study since it is a simple yet robust model that is widely used in literature to simulate the indoor air movement (Sorensen and Nielsen 2003). There are three k- $\varepsilon$ models: standard (SKE), realizable (RKE), and renormalisation group (RNG) model. The standard $\mathrm{k}-\varepsilon$ model was proposed by Launder and Spalding (1972). It is a robust model that can yield acceptable results in many applications. The derivation of the standard $k-\varepsilon$ model equations are based on phenomenological considerations and empiricism (ANSYS 2015). This model was used by (Gao and Niu 2004; Shen, Gao, and Wang 2013; Bin and Sekhar 2007; Yang et al. 2013; Yang and Sekhar 2011; Yang and Sekhar 2014; Gao, Zhang, and Niu 2007; Tham and Pantelic 2010) to study personalized ventilation cases. However, as ANSYS's (2015) user's guide reports, the standard $\mathrm{k}-\varepsilon$ model has some limitations that can lead to inaccurate results of the spreading rate of round jets. Furthermore, the prediction of $\mathrm{k}$ can be unphysical near stagnation points. Therefore, the realizable $\mathrm{k}-\varepsilon$ is more often used (Russo and Khalifa 2010; Habchi et al. 2015; Antoun, Ghaddar, and Ghali 2016; Russo, Dang, and Khalifa 2009; Russo and Khalifa 2011; Makhoul, Ghali, and Ghaddar 2013a; Makhoul et al. 2013; Makhoul, Ghali, and Ghaddar 2013b). The realizable $\mathrm{k}-\varepsilon$ model incorporates a different formulation for the turbulent viscosity than the standard k- $\varepsilon$ model. Furthermore, it contains a modified transport equation for the term $\varepsilon$, which was derived from the transport equation of the mean-square vorticity fluctuation (ANSYS 2015).

The third k- $\varepsilon$ model, the RNG model, implements constants derived from the re-normalization group (RNG) theory instead of empiricism (ANSYS 2015). It was used in similar applications by (He et al. 2011; Liu et al. 2015; Xu et al. 2009; Shuguang 2011; Gao and Zhang 2010; Lo and Novoselac 2010). In addition to offering the advantages of the realizable $\mathrm{k}-\varepsilon$ model, the RNG $\mathrm{k}-\varepsilon$ model contains an improved dissipation rate equation for rapidly strained flows. It also offers turbulence options for swirl dominated flows and a differential viscosity model (ANSYS 2015). All three k- $\varepsilon$ models were tested in this study. Furthermore, other solver settings such as turbulence model options, pressure interpolation schemes were investigated to achieve the best possible agreement between the measured and simulated values.

Subsequently, the validated model was used to study the performance of ductless personalized ventilation system (DPV). The performance of DPV combined with DV was evaluated in this research by comparing air temperature and indoor air quality at the occupant's face when DPV is used to a reference case in which DV is implemented alone. Furthermore, thermal comfort and thermal sensation were calculated using the University of California, Berkeley (UCB) thermal comfort model using results from the CFD simulations. The UCB model was used due to its advanced features that allows simulating non-uniform thermal environments (Huizenga, Zhang, and Arens 2001; Zhang et al. 2010a, 2010b, 2010c; Zhao et al. 2014). The number of body segments in the model is set to 16 ; each segment is divided into four layers: 
core, muscle, fat, and skin, in addition to a fifth layer for heat and moisture transfer through clothing (Voelker et al. 2009).

\section{Validation methodology}

\subsection{Experimental apparatus and setup}

Empirical measurements were performed in the climate chamber of the Department of Building Physics at the Bauhaus-University Weimar. The chamber is a $3 \times 3 \times 2.44 \mathrm{~m}$ room situated in a laboratory hall to keep it isolated from the outdoor environment. The chamber is tempered by waterbearing capillary tubes placed under the finishing layer (tiles for the floor and gypsum plaster for walls and ceiling). The temperature in the chamber can be set between $10-40^{\circ} \mathrm{C}$ by controlling the temperature of each surface separately, or by setting the temperature of the ventilation system, or both. The chamber utilizes two inlets to introduce fresh or recirculated air in an adjustable rate into the chamber. Inlets are located at one of the corners of the chamber (Figure 1), they each consist of a set of 6 pipes with a diameter of $4.5 \mathrm{~cm}$. Concurrently, the system utilizes two outlets with the same dimensions and properties as the inlets. These outlets are located at the opposite corner of the inlets. For this research, only the upper inlet and the upper outlet were utilized to create a mixing ventilation system as the cross-section area of the lower inlet is too small to create a displacement ventilation system.

The climate chamber is equipped with a thermal manikin with complex male body shape that simulates the thermal attributes of a human body. The manikin (nicknamed 'Feelix') is $1.68 \mathrm{~m}$ height in the standing position and $1.23 \mathrm{~m}$ in the upright sitting posture. The manikin body consists of 22 body segments; the temperature of each body segment can be controlled separately through heating nickel wires embedded
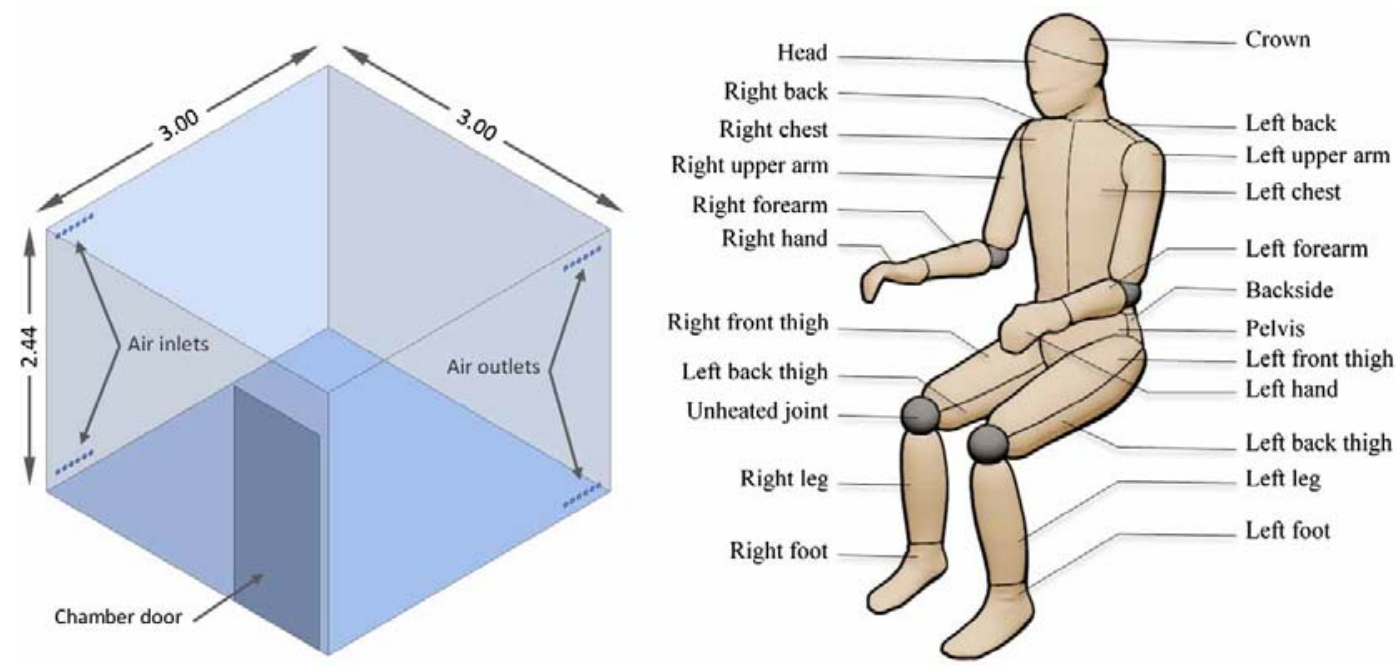

Figure 1 Left: The climate chamber, dimensions are in metre. Right: The thermal manikin
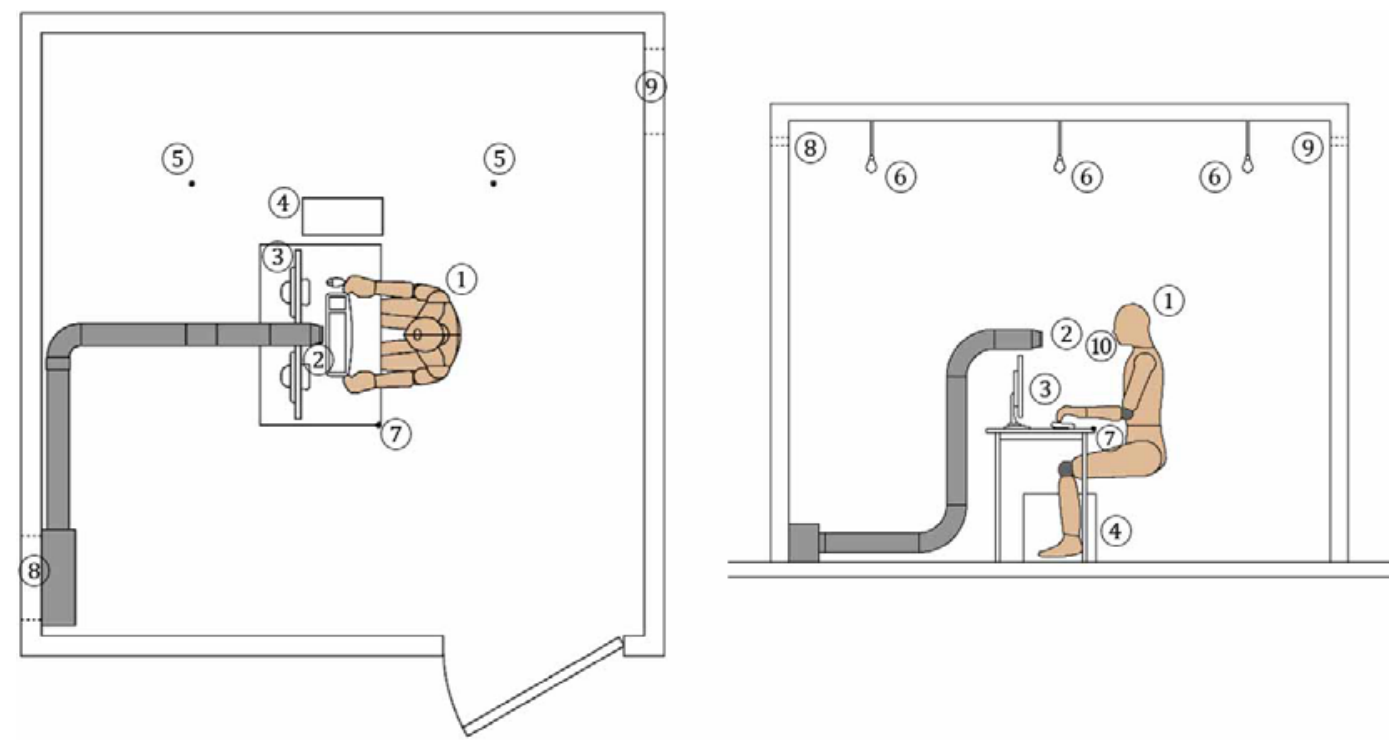

Figure 2 Scheme of the experimental setup in the climate chamber. Left: plan view, right: section view. (1) Thermal manikin, (2) personalized ventilation nozzle, (3) computer monitors, (4) computer case, (5) measurements location of the room's air temperature set-point, (6) ceiling lights, (7) tracer gas dosing location, (8) air inlet location, (9) air outlet location 


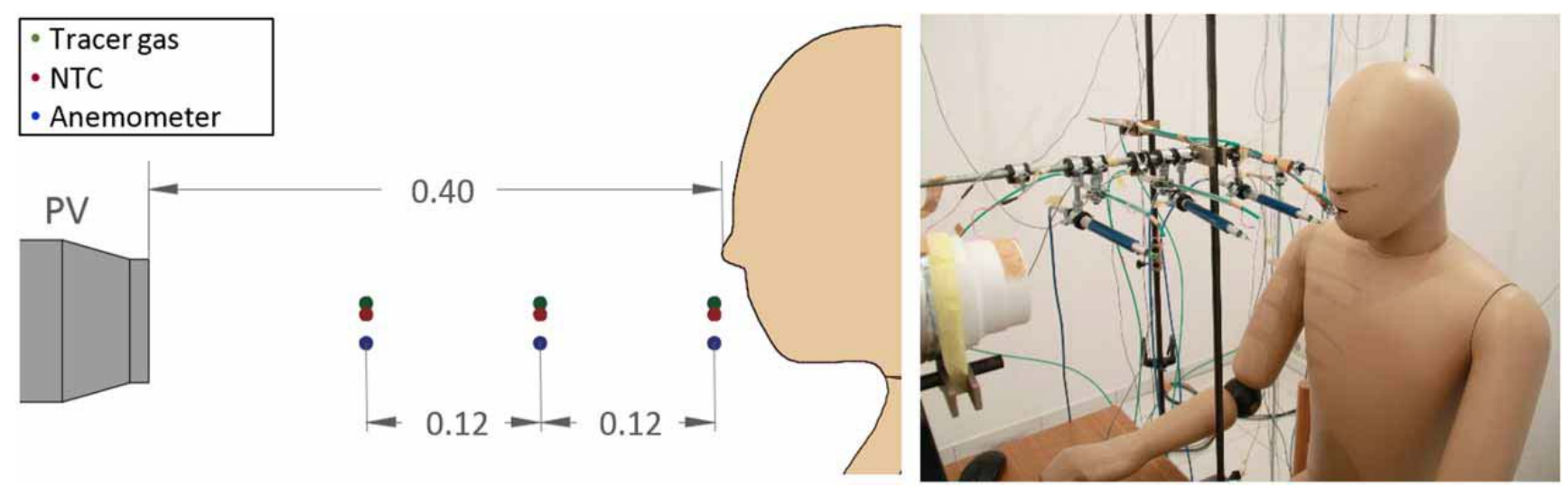

Figure 3 Measurement points in the validation setup. Dimensions are in metre

under the manikin's surface (Figure 1). The manikin surface temperature can be set to simulate a human body in a thermally neutral state (Tanabe et al. 1994), or it can be manually set between $18-42^{\circ} \mathrm{C}$ with a precision of $\pm 0.2^{\circ} \mathrm{C}$.

Negative temperature coefficient thermistors (NTC) with an accuracy of $\pm 0.1 \mathrm{~K}$ of the measured values were used along with hot-wire omni-directional anemometers with an accuracy of $\pm 1.5 \%$ of the measured values to evaluate the thermal environment in the climate chamber. Indoor air quality was evaluated by measuring tracer gas concentrations in the chamber. INNOVA 1412 photoacoustic gas monitor was used to measure $\mathrm{CO}_{2}$ concentrations in the chamber with a detection accuracy of $\pm 2 \%$ of the measured concentration. The INNOVA system was located outside the chamber, air samples were withdrawn into the photoacoustic gas monitor using nylon tubing.

A typical office setup was arranged inside the chamber (Figure 2). The setup consisted of one workstation desk equipped with a desktop computer with two screens. Three halogen light bulbs were mounted on the ceiling as extra heat sources to compensate for heat loads generated by other equipment that can be used in an office, such as a copier or a big printer. An occupant was simulated using the thermal manikin (Melikov 2004b). Since the collected data was intended for CFD validation, the manikin was left bold, naked, and seated on a backless, seatless chair frame to simplify the numerical model. The workstation was equipped with a personalized ventilation system (PV) with a round diffuser (opening diameter $=7.5 \mathrm{~cm}$ ). The $\mathrm{PV}$ outlet was located $40 \mathrm{~cm}$ from the manikin's nose according to the recommendations of Kaczmarczyk et al. (2006) which reports that human subjects preferred personalized ventilation systems that were located $30-45 \mathrm{~cm}$ in front of the face.

\subsection{Measurements}

In order to validate the numerical model, air temperature, velocity, and $\mathrm{CO}_{2}$ concentration were measured at three points between the manikin's face and the PV outlet. The distance between the measurement points was $12 \mathrm{~cm}$. Preliminary measurements showed that having more measurement points causes interference with flow from the
PV and it can lead to unreliable results. Furthermore, it was important to push the measurement points from the PV outlet towards the manikin to decrease the chance of altering the nature of the flow. Through trial and error, it was found that the setup shown in Figure 3 gave the best results compared to measurements with no interfering points between the PV outlet and the manikin's face. Room air temperature was measured and monitored at a height of $1.1 \mathrm{~m}$ from the floor at two locations in the chamber and then averaged (Figure 2). Furthermore, an NTC sensor was affixed to the centre of each surface in the chamber (walls, floor, and ceiling) to accurately define the boundary conditions of these surfaces in the numerical model. Air temperature was also measured at the supply inlet and the exhaust outlet. In order to accurately define the heat flux from the heat sources in the chamber, the power consumed by the computer and the lights was measured using a digital multimeter.

Besides measuring $\mathrm{CO}_{2}$ concentration at the points shown in Figure 3, $\mathrm{CO}_{2}$ concentration was also measured at the supply air duct and the exhaust air duct in order to normalize the concentration. Ventilation effectiveness index (normalized concentration) was used to quantify indoor air quality in order to compare it to the CFD results. It was calculated using equation (1):

$$
\varepsilon_{j}=\frac{C_{e}-C_{s}}{C_{j}-C_{s}}
$$

Where $\varepsilon_{j}=$ ventilation effectiveness at the measured point [-], $C_{e}=$ tracer gas concentration at the exhaust duct $\left[\mathrm{mg} / \mathrm{m}^{3}\right], C_{j}=$ tracer gas concentration at the measured point $\left[\mathrm{mg} / \mathrm{m}^{3}\right], C_{s}=$ tracer gas concentration at the supply duct $\left[\mathrm{mg} / \mathrm{m}^{3}\right]$.

Data were collected under room air temperature setpoint of $\theta_{\text {set-point }}=26^{\circ} \mathrm{C}$, the PV air temperature was set to $3.5 \mathrm{~K}$ lower than the room air. Total heat load in the chamber was 43 $\mathrm{W} / \mathrm{m}^{2}$. The chamber was tempered using only the ventilation system, i.e. the surfaces temperature control function in the climate chamber was turned off. The chamber mixing ventilation flow rate was set to $\dot{V}_{M V}=28 \mathrm{~L} / \mathrm{s}$; PV flow rate was set to $\dot{V}_{P V}=4 \mathrm{~L} / \mathrm{s}$. Thus, the total ventilation flow rate was 32 $\mathrm{L} / \mathrm{s}$, which corresponds to an air change rate of $\mathrm{n}=5.3 \mathrm{~h}^{-1}$. Measured air velocity at the manikin's face was vaface $=0.36$ 
$\mathrm{m} / \mathrm{s}$, which complies with the recommendations of Bolashikov et al. (2003) which state that a minimum velocity of $0.3 \mathrm{~m} / \mathrm{s}$ at the manikin's face is required in order to fully penetrate the thermal boundary layer providing clean air for the inhalation. The relative humidity was always $40-50 \%$ during the measurements.

Since the response time of the INNOVA 1412 photoacoustic gas monitor is relatively long (approximately 27 $\mathrm{s}$ for one gas, $1 \mathrm{~m}$ sampling tube), it is not suitable to study the changes in concentrations caused by a typical breathing frequency of a seated person performing light tasks $(2.5 \mathrm{~s}$ inhalation, $2.5 \mathrm{~s}$ exhalation, $1 \mathrm{~s}$ break, $\dot{V}_{\text {pulmonary }}=6 \mathrm{~L} / \mathrm{min}$ ) (Höppe 1981; Melikov and Kaczmarczyk 2007). Therefore, the breathing function in the manikin was turned off. $\mathrm{CO}_{2}$ was constantly dosed with a flow rate of approximately $\dot{V}_{\mathrm{CO} 2}=3$ $\mathrm{mL} / \mathrm{s}$ into the chamber to simulate a passive contamination source at the corner of the table (dosing location is exhibited in Figure 2). Supply air was set to fresh air (rather than recycled) in order to control the tracer gas measurements. No tracer gas was added to the chamber supplied air nor to the personalized ventilation air.

Before collecting data, the chamber was constantly monitored and given enough leading time to reach a thermal steady state. After steady state was achieved, data was recorded for 1 hour with a sampling interval of $t=5 \mathrm{~s}$ for air temperature, surface temperature, and air velocity measurements. Tracer gas measurements were conducted simultaneously with air temperature and velocity measurement. The steady state of tracer gas concentration was deemed achieved after reaching a steady concentration in the exhaust air, which took about 40 minutes to achieve. The gas monitor was set to a sample integration time of $t_{s I T}=5 \mathrm{~s}$, each sampling point required 3.5 minutes per measurement.

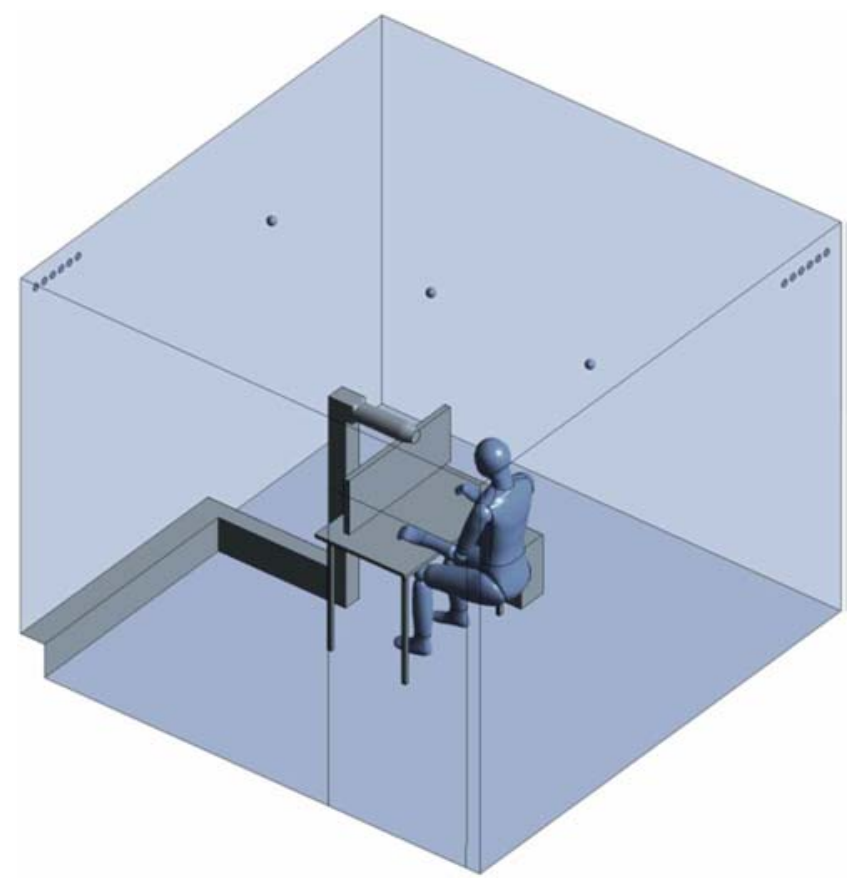

Figure 4 The geometry of the numerical model

\subsection{CFD geometry and mesh settings}

The experimental setup was modelled in ANSYS Design Modeller. Caution was taken to make the numerical model as similar as possible to the empirical experiments by carefully measuring the dimensions of the experimental setup. Furthermore, a 3D laser scanner was used to capture the exact geometry of the thermal manikin in the same sitting posture during the experimental study (Voelker 2011) (Figure 4).

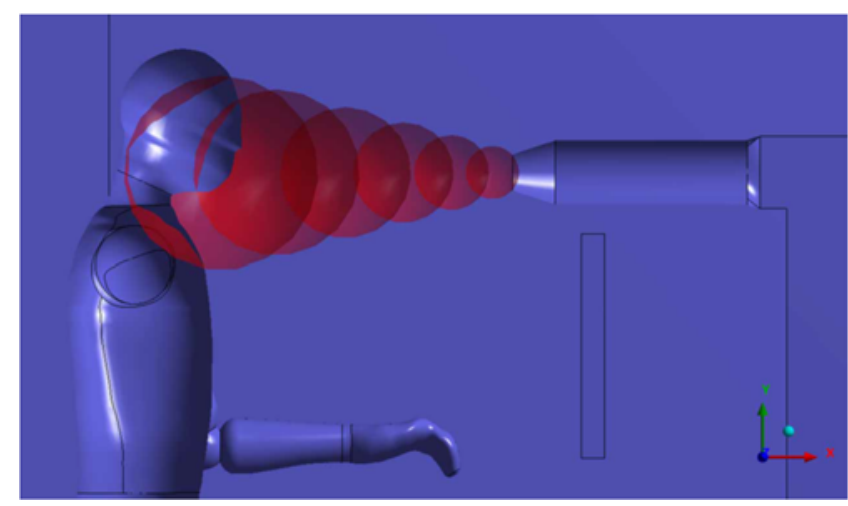

Figure 5 Spheres of influence in the mesh sizing settings

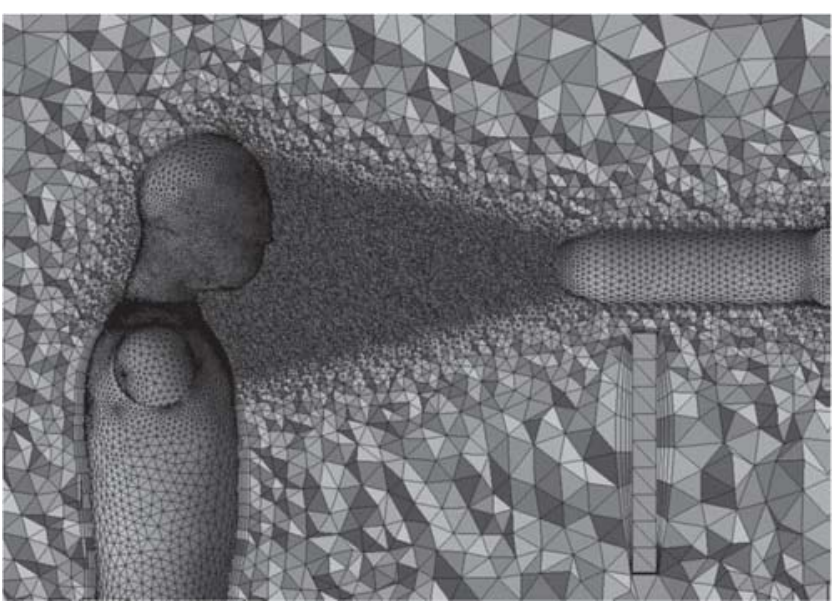

Figure 6 The refined mesh in front of the manikin face

The mesh was generated using the meshing tool in ANSYS Workbench. Test simulations were conducted in order to determine the best mesh properties that yields good results with reasonable computation time. Other factors such as model stability and convergence were taken into account when determining the mesh quality. It was found that a maximum cell size of $0.06 \mathrm{~m}$ works the best. An advanced size function was used to generate the mesh based on proximity and curvature. Two values of the curvature normal angle $\left(12^{\circ}\right.$ and $\left.18^{\circ}\right)$ and two values of the number of cells across gaps (2 and 3 ) were tested. It was found that the default values $\left(18^{\circ}\right.$ with 3 cells across the gap) achieved better results. Critical surfaces such as the inlets and the outlet were refined using a surface sizing function with the following cell sizing settings: chamber inlet and outlet $=0.005 \mathrm{~m}, \mathrm{CO}_{2}$ dosing inlet $=0.0002$ $\mathrm{m}$, and PV inlet $=0.004 \mathrm{~m}$. All sizing functions were set to soft behaviour and a growth rate of $20 \%$. Furthermore, a series of 
6 spheres of influence were created between the PV outlet and the manikins face to refine the mesh in this region (Figure 5). The spheres were arranged to create a cone with an inclination angle of $\sim 15^{\circ}$ to cover the spreading angle of typical radial jets (Krejci et al. 2006). The element size in these spheres was set to $0.004 \mathrm{~m}$.

Inflation layers were created around the manikin, walls, and surfaces in the model to accurately capture the flow properties in the boundary regions. Four inflation layers were created using smooth transition with a default ratio of 0.272 and a growth rate of $20 \%$. The average $y+$ value for the first layer of cells near the manikin surface was $<1$, which is necessary to resolve the wall-bounded turbulent flows -at the cell layers next to the surface where large gradients are expected- without using a wall function for near-wall turbulence modelling (Antoun, Ghaddar, and Ghali 2016; Hjermann 2017; ANSYS 2015). Other inflation schemes were tested such as first layer thickness and first aspect ratio. However, due to the complex geometry of the manikin (especially at the transition to the knees and elbows), smooth transition resulted in a more stable model. These operations led to a final mesh of $\sim 5.77$ million unstructured tetrahedral cells (Figure 6). Maximum skewness of the mesh was 0.9, yet the average was 0.2 . Thus, it can be considered as a high quality mesh (ANSYS 2015).

\subsection{CFD solver and tested models}

The commercial CFD tool ANSYS Fluent was used in this study to solve Reynolds-averaged Navier-Stokes (RANS) equations. The temperature of each segment of the manikin body was assigned in the numerical model using data from the experimental study. Furthermore, each surface at the climate chamber was defined as fixed temperature boundary condition according to their respective measured temperature. The computer case, screens, and lights were defined as fixed heat flux boundary conditions using the values obtained by the digital multimeter during the experimental study. The chamber supply inlet, personalized ventilation nozzle, and the tracer gas dosing point were defined as velocity inlets. The chamber exhaust outlet was modelled as a pressure outlet with $0 \mathrm{~Pa}$ gauge pressure.

Since the simulation cases include heat transfer, airflow, and tracer gas concentrations, four models were implemented in the CFD solver: the flow (RANS) model, the energy model, a turbulence model, and the species transport model. The radiation model S2S was also implemented in preliminary test simulations. Results showed that it had only a small effect on the results since most of the surfaces were defined as fixed temperature boundary condition. Therefore, it was decided not to implement it in the current study to reduce the computation time (Gao and Zhang 2010; Habchi et al. 2015).

All three k- $\varepsilon$ models (SKE, RKE, and RNG) were tested in order to reach the best possible agreement between the measured data and the simulated results. Each turbulence model was tested with two pressure interpolation schemes: second order and PRESTO since those two schemes are widely used in literature. Second order scheme interpolates the face pressure using a second order central differencing scheme. This scheme is the most common scheme because of its accuracy and convergence behaviour. PRESTO scheme is similar to second order, yet it can achieve better results in cases with strong body forces such as high-Rayleigh-number natural convection (ANSYS 2015). The simulated cases are reported in Table 1 .

In order to simulate the buoyancy effects, the incompressible ideal gas law was used for air density. Furthermore, the full buoyancy effects option was implemented based on widely used CFD settings reported in literature. This option incorporates the turbulence generation caused by buoyancy in the value of the dissipation rate $\varepsilon$ too, since the buoyancy effects are included by default in the kinetic energy $\mathrm{k}$ equation in all $\mathrm{k}-\varepsilon$ turbulence models (ANSYS 2015). Coupled pressure-velocity scheme was used along with second order upwind discretization scheme to solve the equations of momentum, turbulent kinetic energy and dissipation rate, energy, and species transport. Convergence criteria were left to their default settings (an absolute value of 0.001 for the residuals of continuity, velocity, turbulence, and species; and an absolute value of $10^{-6}$ for residuals of energy). All the simulated cases implemented enhanced wall treatment (ETH) since it allows switching between the two-layer model and the enhanced wall functions depending on the size of the mesh cells (Makhoul, Ghali, and Ghaddar 2013a; ANSYS 2015). When the mesh is fine enough to capture the viscous sublayer (typically when $y+$ is about 1 ), then the traditional two-layer zonal model is implemented. Yet, when the boundary layer is not resolved $(3<y+<10)$, an enhanced wall function is implemented in order to blend the turbulent law of the wall with the laminar sublayer law to accurately simulate the flow in the boundary layer (Russo, Dang, and Khalifa 2009; ANSYS 2015).

Table 1 The compared simulation setups

\begin{tabular}{lll}
\hline $\begin{array}{l}\text { Case } \\
\text { No. }\end{array}$ & Model setup & Abbreviation \\
\hline 1 & $\begin{array}{l}\text { Standard k- } \varepsilon \text { model with second } \\
\text { order pressure scheme }\end{array}$ & SKE_SO \\
2 & $\begin{array}{l}\text { Standard k- } \varepsilon \quad \text { model with } \\
\text { PRESTO pressure scheme }\end{array}$ & SKE_P \\
3 & $\begin{array}{l}\text { Realizable k- } \varepsilon \text { model with } \\
\text { second order pressure scheme }\end{array}$ & RKE_SO \\
4 & $\begin{array}{l}\text { Realizable k- } \varepsilon \text { model with } \\
\text { PRESTO pressure scheme }\end{array}$ & RKE_P \\
5 & $\begin{array}{l}\text { RNG k- } \varepsilon \text { model with second } \\
\text { order pressure scheme }\end{array}$ & RNG_SO \\
6 & $\begin{array}{l}\text { RNG k- } \varepsilon \text { model with PRESTO } \\
\text { pressure scheme }\end{array}$ & RNG_P \\
& &
\end{tabular}




\section{Results and discussion}
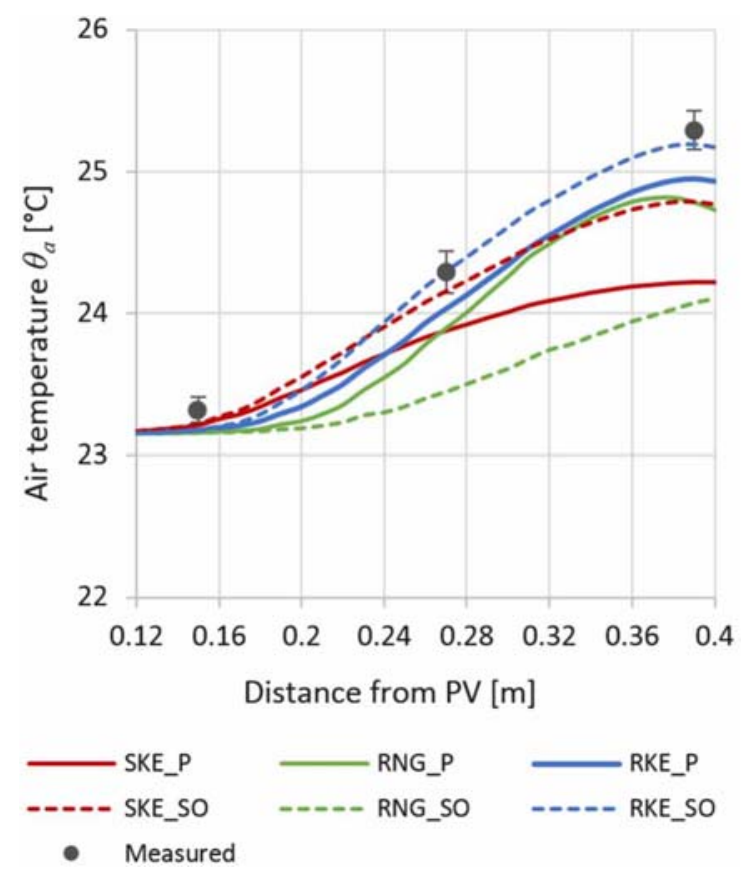

Figure 7 Measured and simulated air temperature between the $P V$ outlet and the manikin's face

The agreement between the measured data and the simulation results was judged by comparing air temperature, velocity, and the ventilation effectiveness index at the measurement points. Figure 7 compares the air temperature in relation to the distance from the PV outlet between the measurements and the simulated cases. The circles on the graph represent the measurement points. The error bars correspond to the standard deviation of the measurements, which indicates the measured fluctuations over time. Results show that the RKE model with second order pressure interpolation scheme (RKE_SO) achieved a good agreement with the measured data. The difference between the average measured air temperature at the measurement locations and the simulation results did not exceed $\Delta \theta=0.14 \mathrm{~K}$. However, RKE model with PRESTO scheme (RKE_P) yielded a maximum temperature difference of $\Delta \theta=0.34 \mathrm{~K}$ in the same locations. On the other hand, RNG model with second order scheme (RNG_SO) resulted in a temperature difference as big as $\Delta \theta=$ $1.22 \mathrm{~K}$ at the manikin's face when comparing measured and simulated values.

Simulated ventilation effectiveness exhibited a similar outcome (Figure 8, left). Both RKE model cases reached the best agreement with the measured data especially at the first measurement point from PV (at $15 \mathrm{~cm}$ from the PV outlet). The RNG model yielded a much higher ventilation effectiveness than the measured value at this location, where $\Delta \varepsilon_{j}=38.64$ when the second order scheme was implemented (RNG_SO). Per contra, the SKE model resulted in a much lower values than the measurement at this point. However, the difference from the measurement at this point was lower than the RNG model results $\left(\Delta \varepsilon_{j}=16.82\right.$ when PRESTO scheme was used).

The right-side chart in Figure 8 exhibits an enlargement of the left-side chart in order to allow for a better judgement of the ventilation effectiveness close to the manikin's face. It shows that the SKE_SO, RNG_P, RKE_P, and RKE_SO cases achieved good agreement with the measured data. Similar to the air temperature results, the RKE model with second order scheme case (RKE_SO) resulted in the best
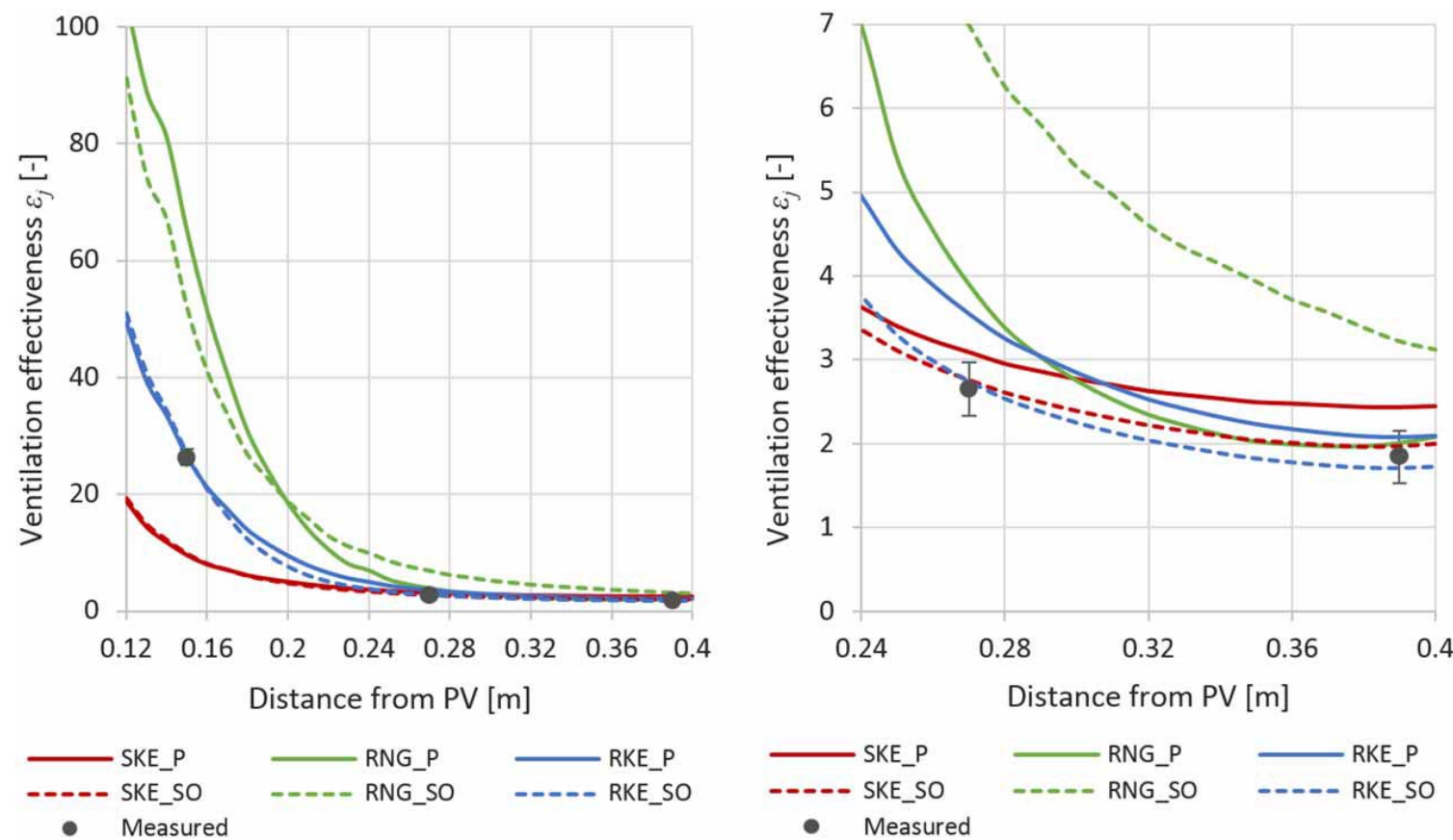

Figure 8 Measured and simulated ventilation effectiveness index between the PV outlet and the manikin's face. The right-side chart is an enlargement of the left-side chart to exhibit the simulated ventilation effectiveness near the manikin's face 
agreement with the ventilation effectiveness measured during the empirical study. During this case, the difference between the measured and simulated ventilation effectiveness at all the three measurement locations was within the range of measurements fluctuations. The RKE_P case also resulted in a good agreement between the measured and simulated values at the manikin's face. On the other hand, the RNG_SO case yielded the least agreement with the measured ventilation effectiveness at the face, where $\Delta \varepsilon_{j}=1.37$.

Simulated air velocity showed different patterns than simulated air temperature and ventilation effectiveness (Figure 9). RKE_SO case resulted in low air velocity compared to other cases. The maximum difference between simulated and measured air velocity during the RKE_SO case was found at the middle measurement point, where $\Delta v=0.16 \mathrm{~m} / \mathrm{s}$. On the other hand, RKE_P case showed a good agreement with the measured air velocity at the manikin's face, and a relatively small deviation from the measured value at the middle measurement point $(\Delta v=0.09 \mathrm{~m} / \mathrm{s})$. In contrast to air temperature and ventilation effectiveness simulations, the RNG_P case achieved the best agreement with the measured data at all the three measurement locations, while the SKE_SO case achieved good agreement with the measured values at the face and the middle measurement point.

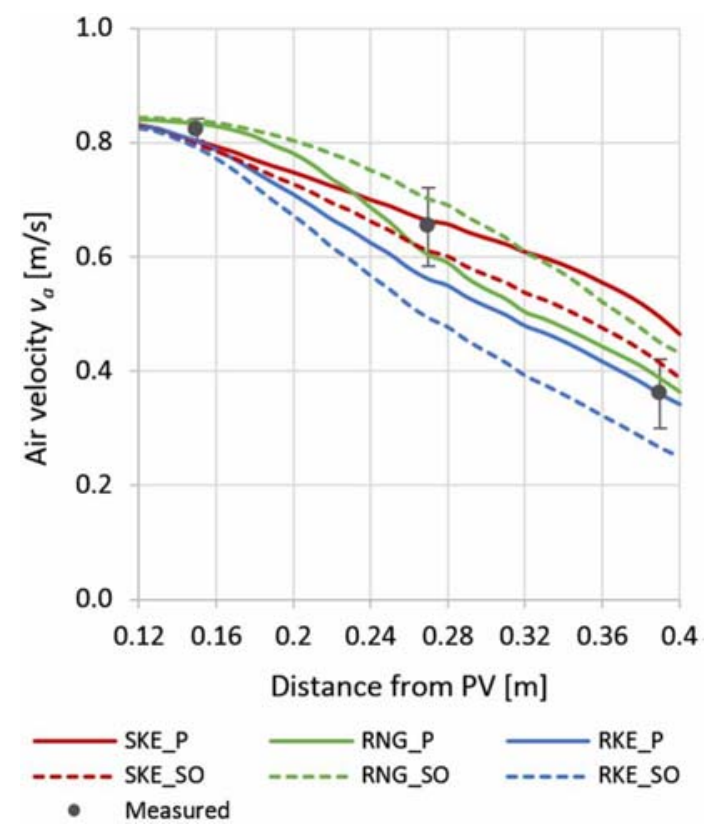

Figure 9 Measured and simulated air velocity between the PV outlet and the manikin's face

After examining the simulation results of air temperature, velocity, and ventilation effectiveness, and considering the stability and convergence of the tested models, it was found that the RKE turbulence model with both second order and PRESTO pressure interpolation schemes achieved the best results compared to the other cases. The SKE model cases reached convergence after less than 1000 iterations. However, the results did not match the measured data. The RNG model yielded good agreement with the measured air velocity. Nevertheless, the numerical model was highly unstable and crashed multiple times. In addition, in some cases, it was difficult to achieve convergence using the RNG model. Therefore, the RKE model was deemed more suitable for this research. The outcome of this study agrees with the recommendations in literature to utilize the RKE model for standard simulation cases because it yields better predictions for spreading rates, flow recirculation, and boundary layers under adverse pressure gradients (ANSYS 2015).

Further simulations were conducted to explore more setting options in the CFD solver. Both enhanced wall treatment (EWT) options (thermal effects and pressure gradient effects) were tested. They showed slight influence on the results accompanied with an acute negative influence on the model's stability and convergence. Therefore, they were not used in this study. Other test simulations were carried out to investigate the influence of disusing the full buoyancy effects option as it was used during the simulation cases presented above. Results showed that not using this option had a minor influence on SKE and RNG cases, in which simulated values were slightly pushed away for the measured values in most cases. Nevertheless, this option was more influential on RKE cases, in which not implementing the full buoyancy effects option caused a disagreement between the measured and simulated values. As an example of this, Figure 10 presents the simulated air velocity during the same cases presented above, yet without utilizing the full buoyancy effects option. As shown in Figure 10, simulated values from both RKE cases fell under the measured values, compared to achieving a good agreement during the RKE_P case when the full buoyancy effects option in used (Figure 9).

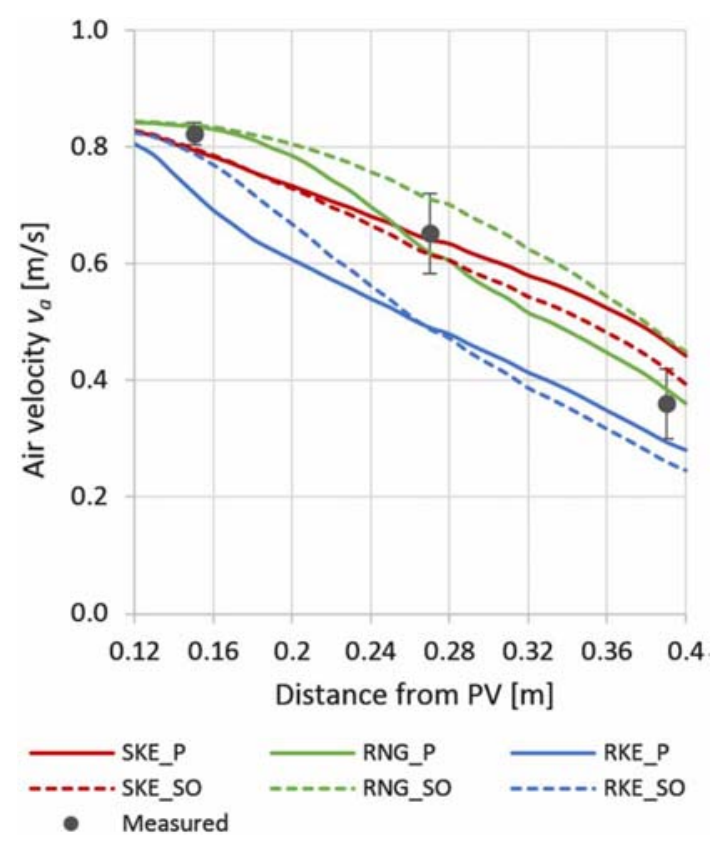

Figure 10 Measured and simulated air velocity between the PV outlet and the manikin's face when the full buoyancy effects option is not implemented 

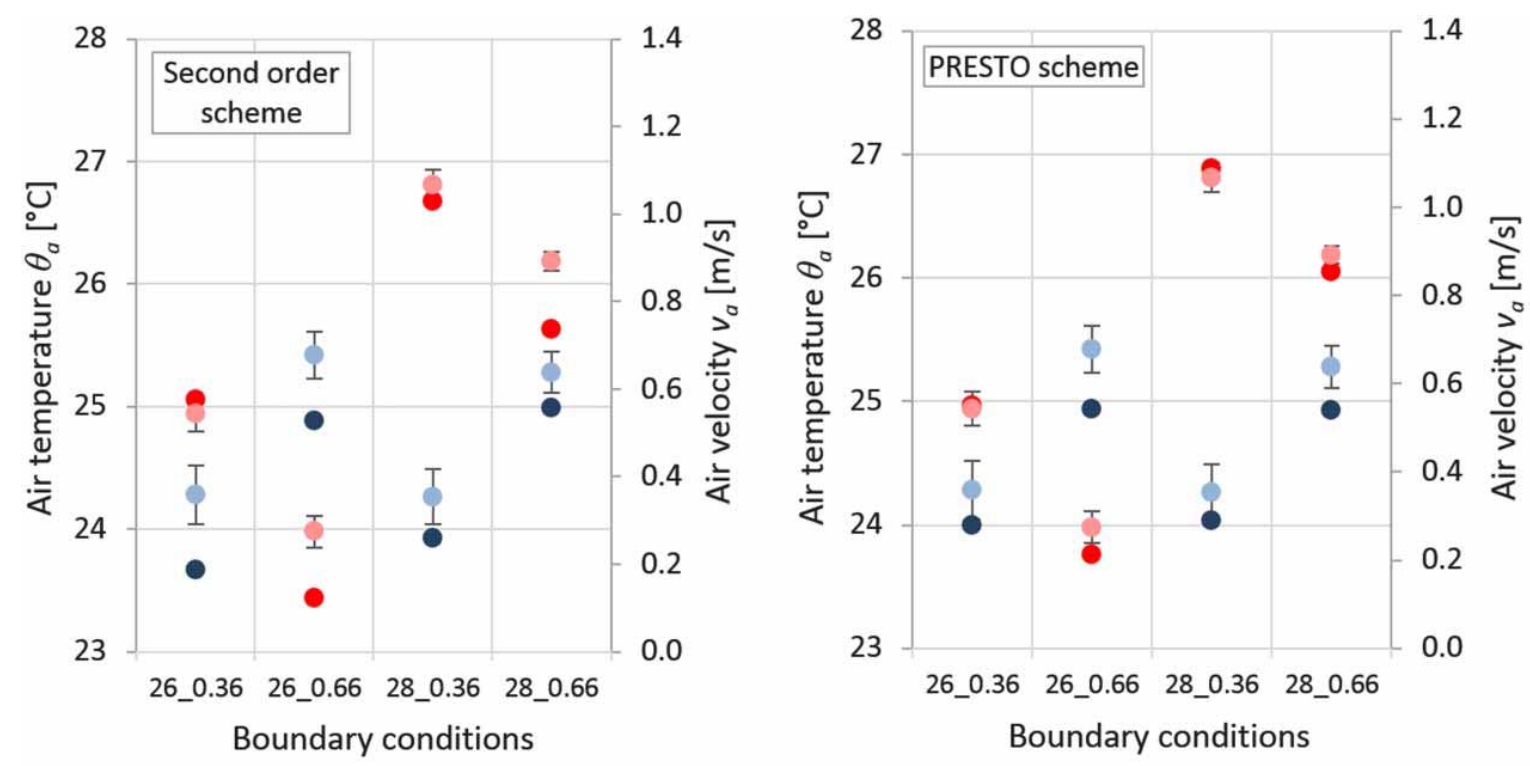

Simulated air temperature Measured air temperature

Simulated air velocity Measured air velocity

Figure 11 Measured and simulated air temperature and velocity at the manikin's face during the simulation cases

\section{Testing the selected turbulence model}

The results reported in section 3 indicate that realizable k- $\varepsilon$ turbulence model (RKE) yielded good agreement with the measure values. It was clear that both second order and PRESTO schemes with RKE turbulence model resulted in good agreement with the measured ventilation effectiveness. However, second order scheme resulted in low air velocity, while PRESTO scheme resulted in low air temperature compared to the measured values. Therefore, more measurements were conducted to determine the better pressure interpolation scheme. The same experimental setup described in the section 2.2 was used for these measurements except that the tracer gas system was not used since the aim was to validate air temperature and velocity. In addition, data were recorded only at the manikin's face in order to eliminate the sensors influence on the flow. Two room air temperature set-points were investigated: $\theta_{\text {set-point }}=26$ and $28^{\circ} \mathrm{C}$, which was measured at a height of $1.1 \mathrm{~m}$ from the floor at two locations in the chamber and then averaged (Figure 2). The temperature of the air supplied by the PV system was lower than the room air temperature by $3 \mathrm{~K}$ during the $\theta_{\text {set-point }}=26^{\circ} \mathrm{C}$ cases and $4 \mathrm{~K}$ during the $\theta_{\text {set-point }}=28^{\circ} \mathrm{C}$ cases. The chamber was tempered using a background mixing ventilation (MV) system and a personalized ventilation system. Similar to the ventilation flow rate used in the experimental study described in section 3 , the total flow rate was set to $\dot{V}=32 \mathrm{~L} / \mathrm{s}$. This flow rate was implemented using two variations: $\dot{V}_{M V}=28 \mathrm{~L} / \mathrm{s}$ with $\dot{V}_{P V}=4$ $\mathrm{L} / \mathrm{s}$, and $\dot{V}_{M V}=27 \mathrm{~L} / \mathrm{s}$ with $\dot{V}_{P V}=5 \mathrm{~L} / \mathrm{s}$. These two setups resulted in an air velocity at the manikin's face of va,face $=0.36$ $\mathrm{m} / \mathrm{s}$ and $0.66 \mathrm{~m} / \mathrm{s}$ respectively. In order to avoid draught discomfort, target velocity values at the face were set lower than the maximum allowed values reported in literature, which reports an individually preferred velocity as high as 1.5 $\mathrm{m} / \mathrm{s}$ at room air temperatures above $26^{\circ} \mathrm{C}$ (Melikov 2004a). Table 2 exhibits the four tested cases.

The same model, mesh, and settings described in section 2.3 was used to allow for direct comparisons. Based on the findings reported in section 3 , the numerical model was solved using the realizable k- $\varepsilon$ turbulence (RKE) model with enhanced wall treatment (EWT) and full buoyancy effects. Each boundary condition case was simulated using both second order and PRESTO pressure interpolation schemes to determine the better scheme.

Table 2 Measurement and simulation cases

\begin{tabular}{lll}
\hline Case No. & Case name & Case description \\
\hline 1 & $26 \_0.36$ & $\theta_{\text {set-point }}=26^{\circ} \mathrm{C}, v_{a, f a c e}=0.36 \mathrm{~m} / \mathrm{s}$ \\
2 & $26 \_0.66$ & $\theta_{\text {set-point }}=26^{\circ} \mathrm{C}, v_{a, f a c e}=0.66 \mathrm{~m} / \mathrm{s}$ \\
3 & $28 \_0.36$ & $\theta_{\text {set-point }}=28^{\circ} \mathrm{C}, v_{a, f a c e}=0.36 \mathrm{~m} / \mathrm{s}$ \\
4 & $28 \_0.66$ & $\theta_{\text {set-point }}=28^{\circ} \mathrm{C}, v_{a, f a c e}=0.66 \mathrm{~m} / \mathrm{s}$ \\
\hline
\end{tabular}

As shown in Figure 11, there was a good agreement between simulated and measured air temperature during the $v_{a, f a c e}=0.36 \mathrm{~m} / \mathrm{s}$ cases, whether second order or PRESTO pressure interpolation schemes was used. Nevertheless, when the flow rate of the PV system was increased to correspond to a target velocity of $v_{a, f a c e}=0.66 \mathrm{~m} / \mathrm{s}$, the second order scheme resulted in lower air temperature at the nose compared to the measured data. Maximum difference between measured and simulated values during the second order cases was $\Delta \theta_{a, f a c e}=$ $0.56 \mathrm{~K}$ during the 28_0.66 case. PRESTO scheme on the other hand resulted in a better agreement between measured and simulated air temperature with a maximum difference of $\Delta \theta_{\text {a,face }}=0.23 \mathrm{~K}$ during the $26 \_0.66$ simulation case. This difference is slightly higher than the standard deviation of the 
measured values during the 26_0.66 case $(\sigma=0.13)$, which is plotted as error bars in Figure 11.

Simulated air velocity at the face exhibited less agreement with the measured values. When second order was used, simulated air velocity was lower than the measured values during all the cases with a maximum difference of $\Delta v_{\text {aface }}=0.17 \mathrm{~m} / \mathrm{s}$ during the $26 \_0.36$ case. PRESTO scheme resulted in better air velocity values compared to second order scheme with an average difference between simulated and measured results of 0.07 and $0.12 \mathrm{~m} / \mathrm{s}$ during the $v_{a, f a c e}=0.36$ $\mathrm{m} / \mathrm{s}$ cases and $v_{a, f a c e}=0.66 \mathrm{~m} / \mathrm{s}$ cases respectively. Thus, by considering all the said factors, it can be said that realizable k$\varepsilon$ model combined with PRESTO scheme achieved the best agreement with the measured data, and it was therefore used to assess the performance of ductless personalized ventilation in this study.

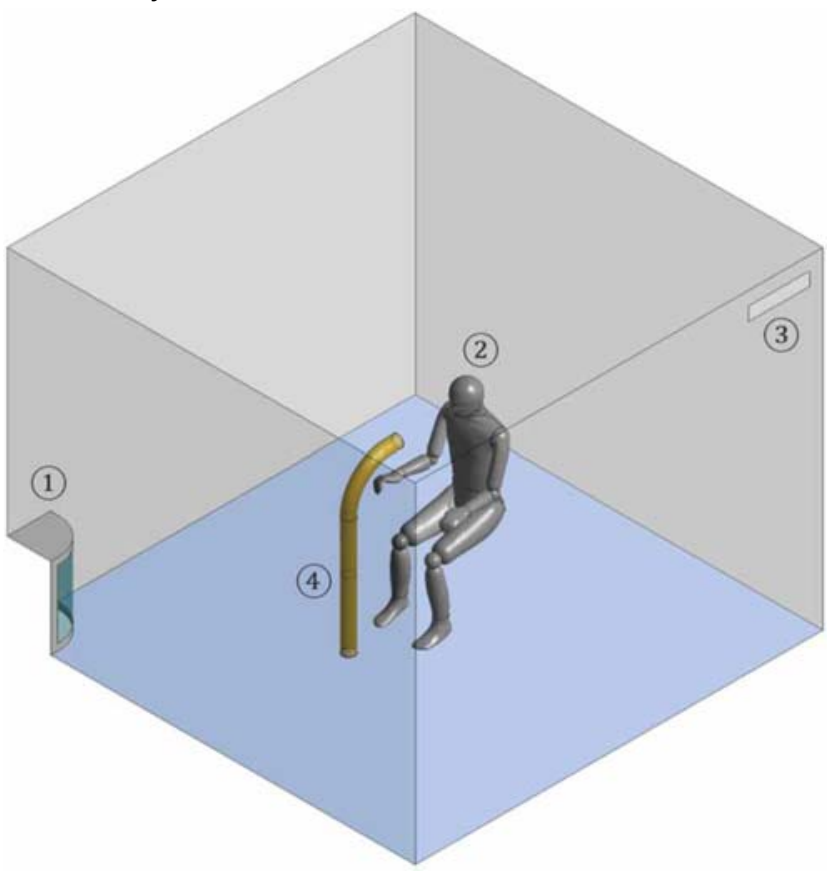

Figure 12 CFD model: (1) displacement ventilation inlet, (2) thermal manikin, (3) exhaust outlet, (4) DPV

\section{Assessing the performance of DPV}

\subsection{CFD simulations}

The model settings validated in section 3 and 4 were used to evaluate the performance of a ductless personalized ventilation system (DPV) combined with displacement ventilation system (DV). DV inlet was modelled as a $60-\mathrm{cm}-$ high corner mounted quarter-cylindrical supply air terminal. DPV was modelled as a pipe with a diameter of $8 \mathrm{~cm}$ mounted in front of the occupant. This 'pipe' is freestanding, i.e. not connected to a duct or another source of air (Figure 12). Since REHVA guidebook reports that the thickness of the first layer of fresh tempered air is $20 \mathrm{~cm}$ above the floor when DV is used (Skistad and Mundt 2002), DPV intake was located $10 \mathrm{~cm}$ above the floor. This also complies with the recommendations of Halvoňová and Melikov (2010). The intake filter suggested by Dalewski, Vesely, and Melikov (2012) was not modelled since dust and other pollutants on floor level were not accounted for during the simulations. DPV outlet was located $40 \mathrm{~cm}$ from the manikin's face according to the findings of Kaczmarczyk et al. (2006). A full description of a DPV system in an actual office was presented by Dalewski, Melikov, and Vesely (2014). The system is mounted on the desk; it consists of 3 parts: (1) air intake equipped with an air filter, (2) an electric fan placed inside a box connected to flexible silencers, (3) an outlet panel connected to a movable arm that allows the user to control the distance between the DPV outlet and the occupant's face. Air flow was controlled by the user through a flow controller located on the desk. In our study, the described simple "pipe" was used in order to reduce the complexity of the numerical model.

Table 3 DPV Simulated cases

\begin{tabular}{ll}
\hline Case & Description \\
\hline DV & Displacement ventilation only (reference case) \\
DPV1 & DV combined with DPV, $\dot{V}_{D P V}=5 \mathrm{~L} / \mathrm{s}$ \\
DPV2 & DV combined with DPV, $\dot{V}_{D P V}=6.5 \mathrm{~L} / \mathrm{s}$ \\
\hline
\end{tabular}

DPV flow rate was set to $\dot{V}_{D P V}=5$ and $6.5 \mathrm{~L} / \mathrm{s}$, which corresponded respectively to an average target velocity of $v_{a, f a c e}=0.33$ and $0.63 \mathrm{~m} / \mathrm{s}$ at the manikin's face. Table 3 summarizes the simulated cases in this research. In order to simplify the simulation, the breathing process was not simulated. Instead, a constant flow of $\mathrm{CO}_{2}$ was introduced into the model through the manikin's mouth to simulate an active contamination source. $\mathrm{CO}_{2}$ was dosed with a flow rate of $\dot{V}_{\mathrm{CO} 2}=$ $3 \mathrm{~mL} / \mathrm{s}$, no tracer gas was added to the air supplied to the chamber. All cases were simulated under climate chamber ventilation rate of $\dot{V}=16,24$, and $43 \mathrm{~L} / \mathrm{s}$, and supply air temperature of $\theta_{s}=19^{\circ} \mathrm{C}$ and $22^{\circ} \mathrm{C}$ for each ventilation rate. Thus, each simulation case reported in Table 3 was simulated 6 times using the above said ventilation setups: $16 \mathrm{~L} / \mathrm{s}_{-} 19^{\circ} \mathrm{C}$, $24 \mathrm{~L} / \mathrm{s} \_19^{\circ} \mathrm{C}, 43 \mathrm{~L} / \mathrm{s} \_19^{\circ} \mathrm{C}, 16 \mathrm{~L} / \mathrm{s} \_22^{\circ} \mathrm{C}, 24 \mathrm{~L} / \mathrm{s} \_22^{\circ} \mathrm{C}$, and 43 $\mathrm{L} / \mathrm{s} \_22^{\circ} \mathrm{C}$. These variations allow evaluating the influence of supplied air temperature and flow rate on the occupant's thermal comfort and indoor air quality.

Thermal sensation and comfort were assessed using the University of California, Berkeley (UCB) thermal comfort model using results from the CFD simulations. The UCB model was also used to investigate the effect of higher relative humidity on the performance of DPV. The model implements a 9-point scale to report the local and overall thermal sensation, in which 4 = very hot, $0=$ neutral, and $-4=$ very cold (Zhang et al. 2010a, 2010c). The model uses a second scale to express local and overall thermal comfort. This scale ranges both upward (where $0=$ just comfortable, 4 = very comfortable), and downward (where $-0=$ just uncomfortable, $-4=$ very uncomfortable) (Zhang et al. 2010b, 2010c). 

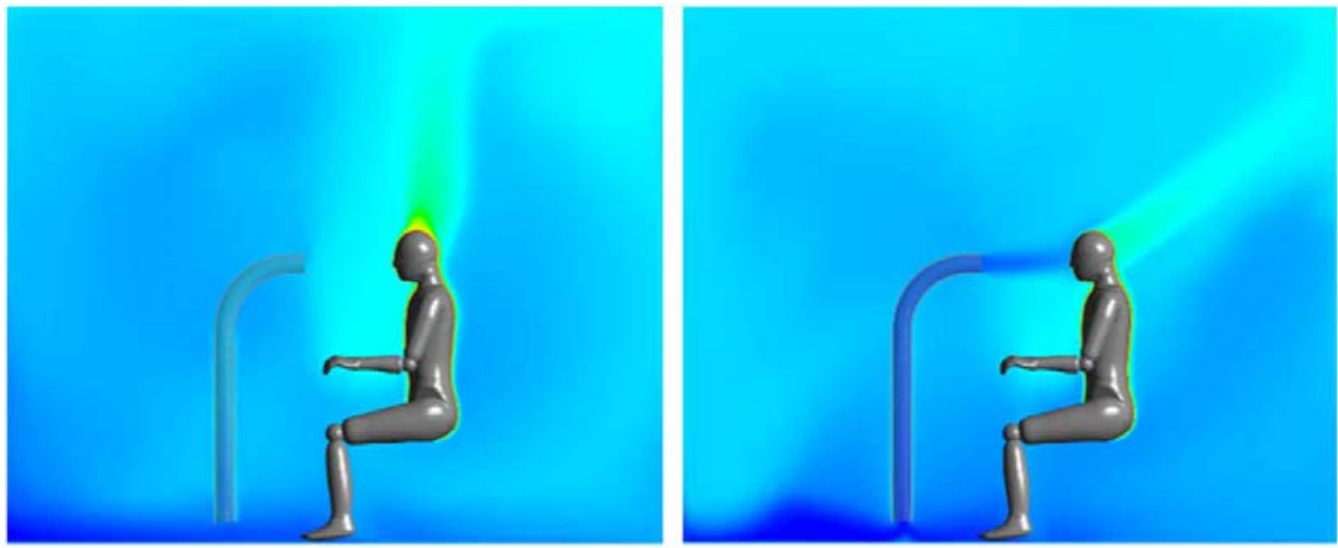

Air temperature $\theta_{a}\left[{ }^{\circ} \mathrm{C}\right]$
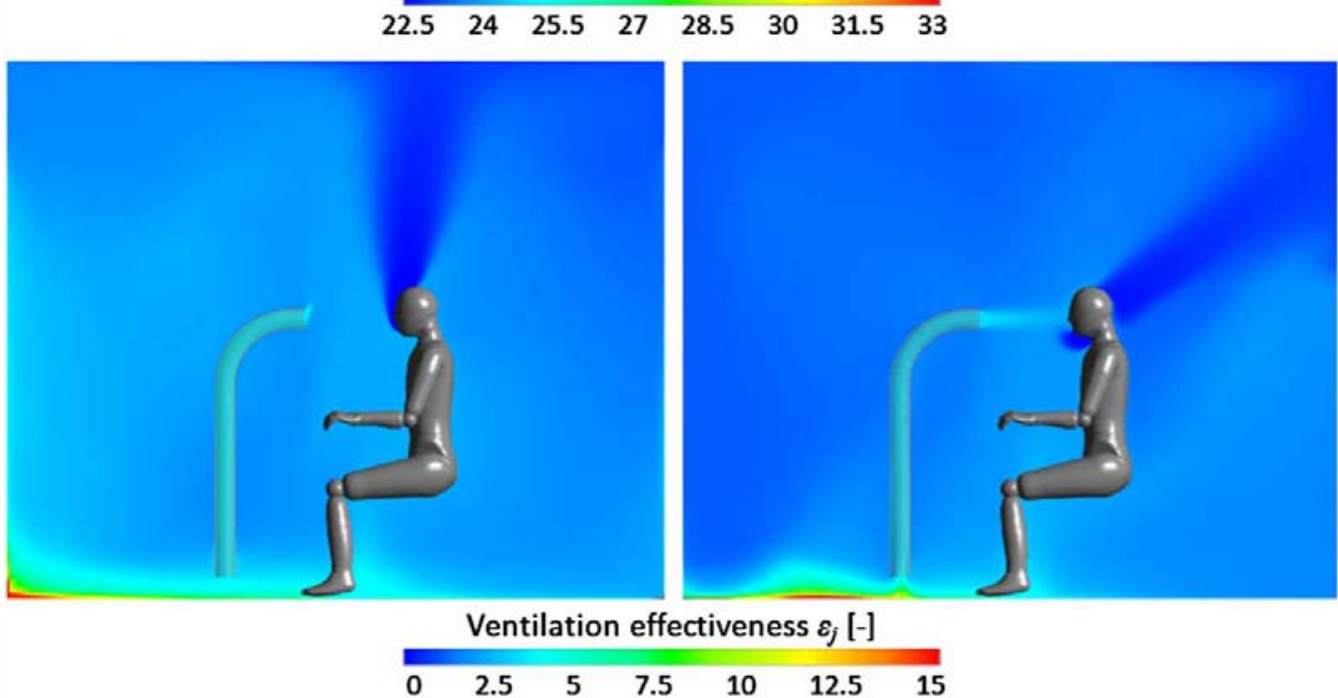

Figure 13 Air temperature and ventilation effectiveness using DV (left) and DPV2 (right) during the $24 L / s_{-} 22^{\circ} \mathrm{C}$ case
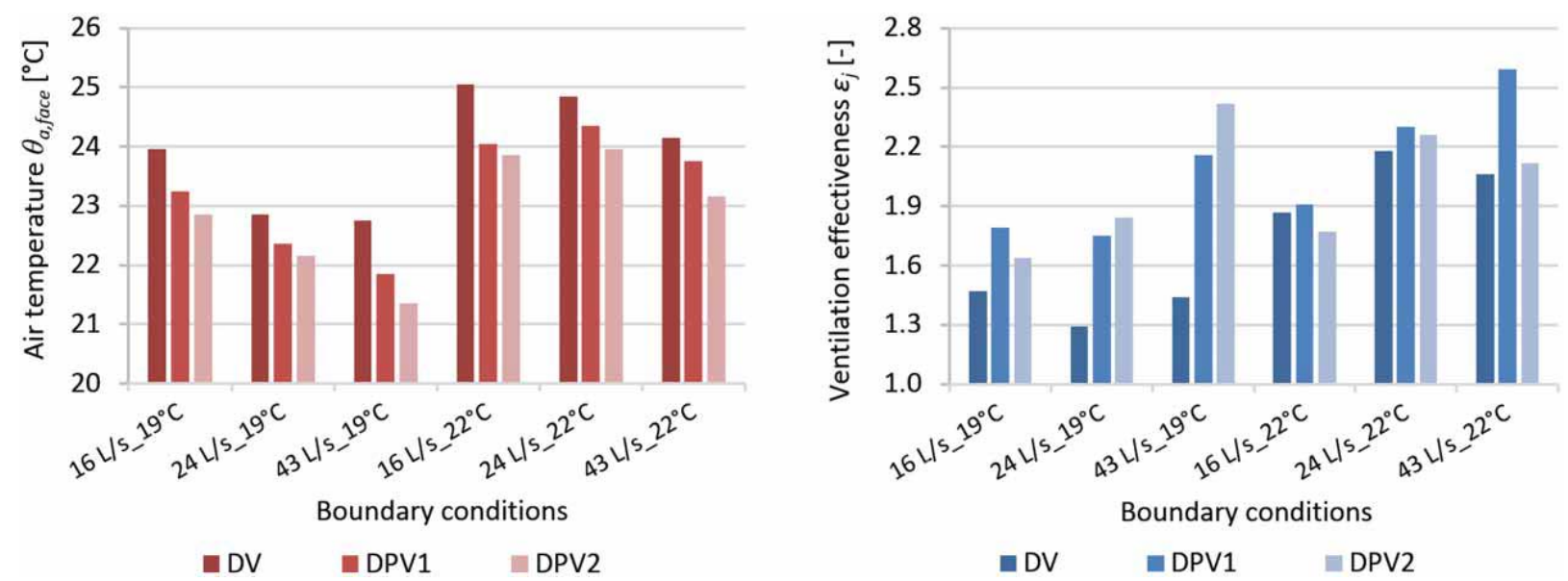

Figure 14 Left: air temperature at the face region during the simulated cases. Right: ventilation effectiveness at the face region during the simulated cases

\subsection{Performance of DPV}

The concept of DPV performance is exhibited in Figure 13 , where DPV transports cool, clean air from the lower layer of the room air and delivers it directly to the occupant's face. As shown in Figure 14 (left), the ductless personalized ventilation system reduces air temperature at the face region.
This reduction is higher during DPV2 cases, in which the flow rate of the ductless personalized ventilation system is higher. The decrease in air temperature at the face region ranged from $\Delta \theta_{\text {a,face }}=-0.4$ to $-1 \mathrm{~K}$ during DPV1 cases. On the other hand, the reduction was $\Delta \theta_{a \text {,face }}=-0.7$ to $-1.4 \mathrm{~K}$ during DPV2 cases. This is due to the larger amount of cool air transported from the floor level to the breathing zone. Interestingly, the same 

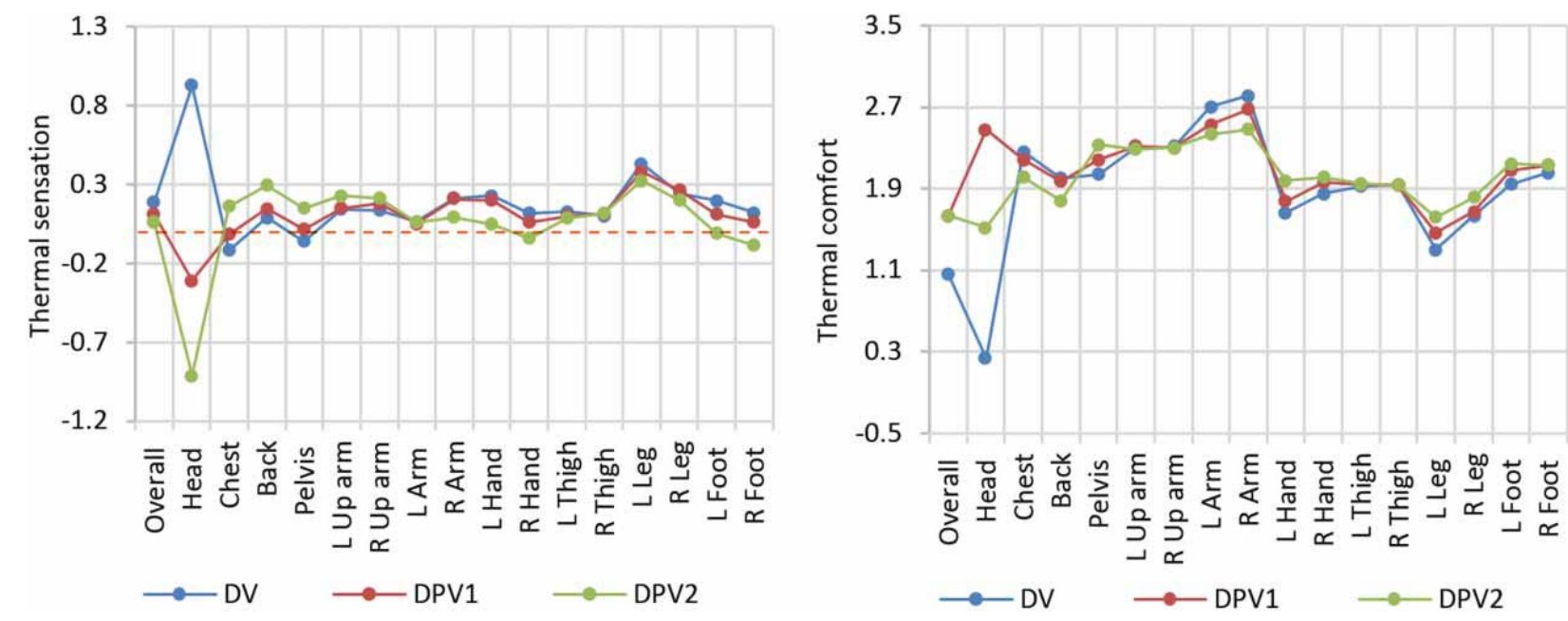

Figure 15 Overall and local thermal sensation (left) and comfort (right) during the $22^{\circ} C_{-} 85 \%$ case. The dotted line on the left-side figure refers to neutral thermal sensation where thermal sensation $=0$

pattern did not apply to the difference in indoor air quality, expressed in the ventilation effectiveness index as shown earlier in equation (1). As shown in Figure 14 (right), higher flow rate from the ductless ventilation system did not necessarily mean a better ventilation effectiveness at the face region. In many cases, DPV2 achieved less ventilation effectiveness than DPV1. A possible explanation for this is that higher flow rate of DPV means higher suction at the intake of DPV, which causes more mixing of air around the intake due to high air momentum. This suction effect can be seen on the right side of Figure 13. Nevertheless, implementing DPV generally leads to significant improvement of ventilation effectiveness of the inhaled air. The improvement of ventilation effectiveness at the face region can be as high as 0.98 when DPV is used compared the reference case of DV alone.

\subsection{Thermal comfort results}

Data acquired from CFD simulations were input into UC Berkeley thermal comfort model in order to investigate thermal sensation and thermal comfort, both overall and local for the 16 body segments defined in the UC Berkeley model. Two cases were selected for investigation using the UC Berkeley model, $16 \mathrm{~L} / \mathrm{s}_{-} 19^{\circ} \mathrm{C}$ and $16 \mathrm{~L} / \mathrm{s} \__{-} 22^{\circ} \mathrm{C}$. Each case was simulated under $60 \%$ and $85 \%$ relative humidity using the same setup cases used in the CFD simulations (DV, DPV1, DPV2). Thus, the investigated cases were $19^{\circ} \mathrm{C}_{-} 60 \%$, $19^{\circ} \mathrm{C} \_85 \%, 22^{\circ} \mathrm{C} \_60 \%$, and $22^{\circ} \mathrm{C} \_85 \%$.

Sixteen probe points were created in the CFD model around the manikin's geometry to export air temperature and velocity around each body segment to the thermal comfort model. Data were transferred to the UCB model manually, advanced approaches of determining undisturbed air temperature described in literature -such as (Voelker and Kornadt 2012) and (Voelker and Alsaad 2017)- were not utilized in this study. Thermal comfort simulations were run using a time constant model, simulation time was $\mathrm{t}=180$ minutes for each case. Metabolic heat generation rate was set to 1.2 met to simulate a busy seated occupant in an office (EN13779 2007).

Results show that the ductless personalized ventilation system alters the thermal sensation into a lower value on the sensation scale. Figure 15 (left) reports the overall and local thermal sensation during the $22^{\circ} \mathrm{C} \_85 \%$ case. Even though overall thermal sensation was not drastically changed $(-0.08$ and -0.13 point with DPV1 and DPV2 respectively), DPV changed the local thermal sensation at the head by up to -1.83 points during the DPV2 setting. Surprisingly, local sensation at some body parts such as chest and back was higher when DPV was implemented. This can be due to redirecting the warm flow of tracer gas from the manikin model's mouth towards the body. Furthermore, inaccuracies resulted by coupling two numerical simulations (CFD and UCB) can be the reason for such unexpected results. The local thermal sensation of other body parts such as hands and feet was colder when DPV was used. This is caused by slight increase in air velocity around these parts, especially the feet, where the suction effect of DPV promoted higher air velocity. The other simulated cases resulted in similar patterns. Maximum decrease in overall warm thermal sensation was -0.47 point during the $19^{\circ} \mathrm{C} \_60 \%$ case.

Thermal comfort results also indicated improvement in some of the simulated cases. Figure 15 (right) shows the overall and local thermal comfort during the $22^{\circ} \mathrm{C} \_85 \%$ case. Both DPV1 and DPV2 improved the overall thermal comfort by 0.58 point. The improvement in thermal comfort was relatively low because the study was conducted under comfortable boundary conditions as a base case study. Furthermore, DPV1 had a better effect on thermal comfort at the head, where local comfort was improved by 2.24 and 1.28 points when using DPV1 and DPV2 respectively. This indicates that the higher air velocity at the head reduced the level of thermal comfort improvement when DPV is used. When the supply air temperature was set to both 19 and $22^{\circ} \mathrm{C}$, DPV2 negatively affected thermal comfort due to the combination of high air velocity with relatively low temperature. DPV1 
improved local thermal comfort at the head by only 0.09 point during $19^{\circ} \mathrm{C} \_85 \%$ case, and impaired thermal comfort during the $19^{\circ} \mathrm{C} \_60 \%$ case. This suggests that DPV can induce contrary results when the air temperature in the chamber is already at a comfortable level. This effect is more acute with higher flow rates of DPV. This agrees with the recommendation reported in literature of providing high $\mathrm{PV}$ velocities when the room air temperature is higher than $26^{\circ} \mathrm{C}$ (Melikov 2004a; Dalewski, Melikov, and Vesely 2014).

The other body parts experienced slight changes in thermal comfort when the systems were implemented during all of the simulated cases. This is due to minor changes in air temperature and velocity around these parts when DPV1 and DPV2 were used. Additional supplementary information about the thermal sensation and thermal comfort results during the other simulated cases are available in the online version of this article.

\section{Conclusions, limitations, and future research}

The conclusions of this study can be summarized in two bullet points according to the twofold aim of the research stated earlier in the introduction:

- Prior to evaluating the indoor environment using computational fluid dynamics (CFD), the numerical model must be first validated against measured data. Validation experiments and simulations showed that realizable $\mathrm{k}-\varepsilon$ turbulence model achieved good agreement between measured and simulated values compared to other k- $\varepsilon$ turbulence models. Both tested pressure interpolation schemes (second order and PRESTO) resulted in good agreement between measured and simulated ventilation effectiveness. However, second order resulted in better prediction of air temperature while PRESTO achieved better prediction of air velocity. Further validation investigations showed that PRESTO scheme is generally more suitable than second order.

- Computational fluid dynamics simulations showed that employing ductless personalized ventilation systems can improve the indoor environment around the occupants. Thermal comfort simulations showed that the DPV can improve overall thermal sensation and local thermal sensation around the head. Moreover, it can enhance the thermal comfort, both overall and locally. However, these results are highly dependent on the air temperature in the room. The system performs better with higher air temperatures and relative humidity. On the contrary, the system can decrease comfort when used with relatively low air temperatures. Inhaled indoor air quality investigations showed also a significant improvement when the ductless system was used. DPV increased the ventilation effectiveness index by up to 0.98 compared to the reference case where DPV was not used. However, lower DPV flow rate can improve the inhaled indoor air quality better than higher DPV flow rate due to higher air mixing around the system intake.

Based on the above conclusions, ductless personalized ventilation can be a novel tool to improve the indoor environment. Its flexibility and relatively lower cost give it advantage over the regular ducted personalized ventilation. However, the conclusions reported above should be considered in the light of the limitations that this study encountered. A major limitation in this study was conducting the validation work using mixing ventilation (MV) system instead of displacement ventilation (DV) since the climate chamber is not equipped with a displacement ventilation diffuser. Further investigations are required to make sure the selected CFD settings achieve good results for both MV and DV systems, even though these systems have different characteristics in terms of indoor air distribution and interaction with the human convective boundary layer.

The performance of DPV also requires further study. As the focus of this work is on the validation of the numerical model, the performance of DPV was evaluated in a simple model that consists of only an occupant in an empty room to test the selected CFD settings. Further research is being currently conducted by the authors to directly compare the performance of ducted and ductless personalized ventilation in a complex office setup. Furthermore, the influence of various variables, such as turbulence intensity, nature of the flow, contamination sources, furniture arrangement, and occupants' distribution in the room need to be considered when studying the performance of personalized ventilation systems.

\section{Acknowledgements}

This work was supported by a scholarship from the Deutscher Akademischer Austauschdienst (DAAD) under the Research Grants - Doctoral Programmes in Germany (programme ID: 57129429). Their constant support is highly cherished and appreciated.

\section{Supporting information}

Supplementary information can be found in the online version of this article:

- Figure S1. Overall thermal sensation during the investigated cases.

- Figure S2. Local thermal sensation at the head during the investigated cases.

- Figure S3. Overall thermal comfort during the investigated cases.

- Figure S4. Local thermal comfort at the head during the investigated cases. 


\section{References}

ANSYS. 2015. ANSYS® Academic Research, Release 16.2, Help System, Coupled Field Analysis Guide. www.ansys.com.

Antoun, Sylvie, Nesreen Ghaddar, and Kamel Ghali. 2016. "Coaxial personalized ventilation system and window performance for human thermal comfort in asymmetrical environment." Energy and Buildings 111: 253-66.

ASHRAE. 2009. 2009 ASHRAE Handbook: Fundamentals. Atlanta, GA: American Society of Heating, Refrigeration and Air-Conditioning Engineers.

Bin, Yang, and S. C. Sekhar. 2007. "Three-dimensional numerical simulation of a hybrid fresh air and recirculated air diffuser for decoupled ventilation strategy." Building and Environment 42 (5): 1975-82.

Bolashikov, Zhecho D., L. Nikolaev, Arsen K. Melikov, Jan Kaczmarczyk, and Povl O. Fanger. 2003. "Personalized ventilation: air terminal devices with high efficiency." In: Proceedings of Healthy Buildings 2003: ISIAQ 7th International Conference, Singapore, 850-55.

Dalewski, Mariusz, Arsen K. Melikov, and Michal Vesely. 2014. "Performance of ductless personalized ventilation in conjunction with displacement ventilation: Physical environment and human response." Building and Environment 81: 354-364.

Dalewski, Mariusz, Michal Vesely, and Arsen K. Melikov. 2012. "Ductless personalized ventilation with local air cleaning." In: Proceedings of Healthy Buildings 2012: ISIAQ 10th International Conference, Brisbane, Australia, 1: $1-6$.

EN13779. 2007. Ventilation for non-residential buildings Performance requirements for ventilation and roomconditioning systems; German version EN 13779: DIN Deutsches Institut für Normung.

Fanger, Povl 0. 1970. Thermal Comfort: McGraw-Hill, New York, USA.

Gao, N. P., H. Zhang, and J. L. Niu. 2007. "Investigating Indoor Air Quality and Thermal Comfort Using a Numerical Thermal Manikin." Indoor and Built Environment 16 (1): 7-17.

Gao, Naiping, and Jianlei Niu. 2004. "CFD study on microenvironment around human body and personalized ventilation." Building and Environment 39 (7): 795-805.

Gao, Zhi, and J. S. Zhang. 2010. "Numerical analysis for evaluating the "Exposure Reduction Effectiveness" of room air cleaners." Building and Environment 45 (9): 1984-92.

Habchi, Carine, Kamel Ghali, Nesreen Ghaddar, and Alan Shihadeh. 2015. "Chair fan-enhanced displacement ventilation for high IAQ: Effects on particle inhalation and stratification height." Building and Environment 84: 68-79.

Halvoňová, Barbora, and Arsen K. Melikov. 2010. "Performance of "ductless" personalized ventilation in conjunction with displacement ventilation: Impact of intake height." Building and Environment 45 (4): 9961005.

He, Qibin, Jianlei Niu, Naiping Gao, Tong Zhu, and Jiazheng Wu. 2011. "CFD study of exhaled droplet transmission between occupants under different ventilation strategies in a typical office room." Building and Environment 46 (2): 397-408.

Hjermann, Tollef. 2017. "CFD simulation of active displacement ventilation." Master thesis, Norwegian University of Science and Technology, Department of Energy and Process Engineering.

Höppe, P. 1981. "Temperatures of expired air under varying climatic conditions." Int J Biometeorol 25 (2): 127-32.

Huizenga, Charlie, Hui Zhang, and Edward Arens. 2001. "A model of human physiology and comfort for assessing complex thermal environments." Building and Environment 36 (6): 691-99.

Kaczmarczyk, J., A. Melikov, Z. Bolashikov, L. Nikolaev, and P. O. Fanger. 2006. "Human Response to Five Designs of Personalized Ventilation." HVAC\&R Res. 12 (2): 367-84.

Krejci, Vladimir, Jan Kosner, Tomas Peciva, and Martin Kaplan. 2006. "Flow pattern generated by a radial jet." In: Proceedings of 8th International Conference VENT 2006. Chicago, USA.

Kuzmin, Dmitri. n.d. Introduction to Computational Fluid Dynamics. Institute of Applied Mathematics, University of Dortmund, USA. Accessed July 2017. http://www.mathematik.unidortmund.de/ kuzmin/cfdintro/cfd.html.

Kuzmin, Dmitri. 2010. A guide to numerical methods for transport equations. University Erlangen-Nuremberg, Bavaria, Germany.

Launder, B. E., and D. B. Spalding. 1972. Lectures in mathematical models of turbulence. London: Academic Press.

Lipczynska, Aleksandra, Jan Kaczmarczyk, and Arsen K Melikov. 2014. "Performance of radiant cooling ceiling combined with personalized ventilation in an office room: identification of thermal conditions." In: Proceedings of 13th International Conference on Indoor Air Quality and Climate. Hong Kong.

Liu, Taishun, Zeqin Liu, Ge Li, and Zhenjun Zuo. 2015. "Comparative Study of Numerical Simulation of Indoor Thermal Environment in the Pattern of Personalized Ventilation and Stratum Ventilation." Procedia Engineering 121: 785-91.

Lo, L. J., and Atila Novoselac. 2010. "Localized air-conditioning with occupancy control in an open office." Energy and Buildings 42 (7): 1120-28.

Makhoul, A., K. Ghali, and N. Ghaddar. 2013a. "Desk fans for the control of the convection flow around occupants using ceiling mounted personalized ventilation." Building and Environment 59: 336-48.

Makhoul, A., K. Ghali, and N. Ghaddar. 2013b. "Thermal comfort and energy performance of a low-mixing ceiling- 
mounted personalized ventilator system." Building and Environment 60: 126-36.

Makhoul, A., K. Ghali, N. Ghaddar, and W. Chakroun. 2013. "Investigation of particle transport in offices equipped with ceiling-mounted personalized ventilators." Building and Environment 63: 97-107.

Melikov, A., and J. Kaczmarczyk. 2007. "Measurement and prediction of indoor air quality using a breathing thermal manikin." Indoor air 17 (1): 50-59.

Melikov, A. K. 2004a. “Personalized ventilation.” Indoor air 14 (s7): 157-67.

Melikov, Arsen. 2004b. "Breathing thermal manikins for indoor environment assessment: important characteristics and requirements." European journal of applied physiology 92 (6): 710-13.

Nielsen, Peter V. 2015. "Fifty years of CFD for room air distribution." Building and Environment 91: 78-90.

Russo, Jackie, and Khalifa, H. E. 2011. Computational study of personal ventilation with multiple occupants and various configurations. In: Proceedings of ROOMVENT 2011, Trondheim, Norway.

Russo, Jackie S., Thong Q. Dang, and Khalifa, H. E. 2009. "Computational analysis of reduced-mixing personal ventilation jets." Building and Environment 44 (8): 155967.

Russo, Jackie S., and Khalifa, H. E. 2010. "CFD assessment of intake fraction in the indoor environment." Building and Environment 45 (9): 1968-75.

Shen, Chong, Naiping Gao, and Tingquan Wang. 2013. "CFD study on the transmission of indoor pollutants under personalized ventilation." Building and Environment 63: 69-78.

Shuguang, Huang. 2011. "Experimental and numerical study on personalized ventilation coupled with displacement ventilation." Master's thesis, Department of Building, National University of Singapore.

Skistad, Håkon, and Elisabeth Mundt. 2002. Displacement ventilation in non-industrial premises. REHVA guidebook no. 1. Brussels: REHVA, Federation of European Heating and Air-conditioning Associations.

Sorensen, D. N., and P. V. Nielsen. 2003. "Quality control of computational fluid dynamics in indoor environments." Indoor air 13 (1): 2-17.

Tanabe, S., Edward A. Arens, Fred Bauman, H. Zhang, and T. Madsen. 1994. "Evaluating thermal environments by using a thermal manikin with controlled skin surface temperature." ASHRAE Transactions 100 (Part 1): 39-48.

Tham, Kwok W., and Jovan Pantelic. 2010. "Performance evaluation of the coupling of a desktop personalized ventilation air terminal device and desk mounted fans." Building and Environment 45 (9): 1941-50.

Voelker, Conrad. 2011. "Entwicklung und messtechnische Validierung der Kopplung von CFD-Simulation mit einem thermophysiologischen Modell zur Bestimmung der thermischen Behaglichkeit [Development and measurement validation of the coupling of CFD simulation with a thermophysiological model for the determination of thermal comfort]." Ph.D. dissertation, Bauhaus-University Weimar, Department of Building Physics.

Voelker, Conrad, and Hayder Alsaad. 2018. "Simulating the human body's microclimate using automatic coupling of CFD and an advanced thermoregulation model. Indoor air, 28(3), 415-425.

Voelker, Conrad, Sabine Hoffmann, Oliver Kornadt, Edward Arens, Hui Zhang, and Charlie Huizenga. 2009. "Heat and moisture transfer through clothing." In: Proceedings of Building Simulation: the 11th international IBPSA conference, Glasgow, Scotland, 1360-66.

Voelker, Conrad, and Oliver Kornadt. 2012. "Automated coupling of CFD and human thermoregulation modellingconsidering local climatic parameters." In: Proceedings of the 5th International Building Physics Conference IBPC, Kyoto, Japan, 945-51.

$\mathrm{Xu}$, Yue, Xudong Yang, Caiqing Yang, and Jelena Srebric. 2009. "Contaminant dispersion with personal displacement ventilation, Part I: Base case study." Building and Environment 44 (10): 2121-28.

Yang, Bin, and Chandra Sekhar. 2014. "Interaction of dynamic indoor environment with moving person and performance of ceiling mounted personalized ventilation system." Indoor and Built Environment 23 (7): 920-32.

Yang, Junjing, and Chandra Sekhar. 2011. "Computational analyses of the performance of personalizedventilation system in conjunction with personalized exhaust." In: Proceedings of ROOMVENT 2011, Trondheim, Norway, 19-22.

Yang, Junjing, Chandra Sekhar, David C. K. Wai, and Benny Raphael. 2013. "Computational fluid dynamics study and evaluation of different personalized exhaust devices." HVAC\&R Research 19 (8): 934-46.

Zhang, Hui, Edward Arens, Charlie Huizenga, and Taeyoung Han. 2010a. "Thermal sensation and comfort models for non-uniform and transient environments: Part I: Local sensation of individual body parts." Building and Environment 45 (2): 380-88.

Zhang, Hui, Edward Arens, Charlie Huizenga, and Taeyoung Han. 2010b. "Thermal sensation and comfort models for non-uniform and transient environments, part II: Local comfort of individual body parts." Building and Environment 45 (2): 389-98.

Zhang, Hui, Edward Arens, Charlie Huizenga, and Taeyoung Han. 2010c. "Thermal sensation and comfort models for non-uniform and transient environments, part III: Whole-body sensation and comfort." Building and Environment 45 (2): 399-410.

Zhao, Yin, Hui Zhang, Edward A. Arens, and Qianchuan Zhao. 2014. "Thermal sensation and comfort models for nonuniform and transient environments, part IV: Adaptive neutral setpoints and smoothed whole-body sensation model." Building and Environment 72: 300-308. 